\title{
Risk-Taking Behavior in a Gambling Task Associated with Variations in the Tryptophan Hydroxylase 2 Gene: Relevance to Psychiatric Disorders
}

\author{
Gabriella Juhasz*,', Darragh Downey', Neal Hinvest', Emma Thomas', Diana Chase', Zoltan G Toth², \\ Kathryn Lloyd-Williams', Krisztina Mekli, 3,4, Hazel Platt ${ }^{3}$, Antony Payton ${ }^{3}$, Gyorgy Bagdy ${ }^{4,5}$, \\ Rebecca Elliott', JF William Deakin' and Ian M Anderson' \\ 'Neuroscience and Psychiatry Unit, School of Community Based Medicine, Faculty of Medical and Human Sciences, The University of \\ Manchester, Manchester, UK; ${ }^{2}$ Faculty of Life Sciences, The University of Manchester, Manchester, UK; ${ }^{3}$ Centre for Integrated Genomic Medical \\ Research, School of Translational Medicine, Faculty of Medical and Human Sciences, The University of Manchester, Manchester, UK; \\ ${ }^{4}$ Department of Pharmacology and Pharmacotherapy, Faculty of Medicine, Semmelweis University, Budapest, Hungary; ${ }^{5}$ Department of \\ Pharmacodynamics, and Group of Neurochemistry, Hungarian Academy of Sciences and Semmelweis University, Budapest, Hungary
}

\begin{abstract}
Decision making, choosing the best option from the possible outcomes, is impaired in many psychiatric conditions including affective disorders. We tested the hypothesis that variations in serotonergic genes (TPH2, TPHI, SLC6A4, HTRIA), which influence serotonin availability, affect choice behavior in a probabilistic gambling task. A population cohort $(N=1035)$ completed a paper-and-pencil gambling task, filled out personality and symptom questionnaires and gave consent for the use of their DNA in a genetic association study. A subgroup of subjects $(N=69)$ also completed a computer version of the task. The gambling task was designed to estimate an individual's tendency to take a risk when choosing between a smaller but more certain 'win' and a larger, less probable one. We genotyped seven haplotype tagging SNPs in the TPH2 gene, and previously reported functional polymorphisms from the other genes (rs / 800532, 5HTTLPR, and rs6295). Carriers of the more prevalent TPH2 haplotype, which was previously associated with less active enzyme variant, showed reduced risk taking on both tasks compared with subjects not carrying the common haplotype. The effect of $\mathrm{TPH} 2$ haplotypes on risk-taking was independent of current depression and anxiety symptoms, neuroticism and impulsiveness scores. We did not find an association between functional polymorphisms in the TPHI, SLC6A4, HTRIA genes and risk-taking behavior. In conclusion, our study demonstrates the role of the TPH2 gene and the serotonin system in risk taking and suggests that $T P H 2$ gene may contribute to the expression of psychiatric phenotypes through altered decision making.

Neuropsychopharmacology (2010) 35, II09-I I 9; doi:I0.1038/npp.2009.216; published online 30 December 2009
\end{abstract}

Keywords: risk taking; TPH2; haplotype analysis; depression; psychiatric disorders

\section{INTRODUCTION}

Decision making depends on a complex set of processes that are orchestrated in various brain systems to find an optimal outcome (Elliott and Deakin, 2005; Paulus, 2007). Risktaking refers to the willingness to accept a possible negative outcome in order to potentially achieve a desirable outcome, and typically involves assessing the relative probability of winning or losing against the values of the outcomes (Anderson et al, 2003; Cardinal, 2006). Subjects

*Correspondence: Dr G Juhasz, Neuroscience and Psychiatry Unit, School of Community Based Medicine, Faculty of Medical and Human Sciences, The University of Manchester, Stopford Building, Oxford Road, Manchester MI3 9PT, UK, E-mail: gabriella.juhasz@manchester. ac.uk

Received 22 June 2009; revised 20 November 2009; accepted 23 November 2009 with depression or anxiety are less likely than controls to take risks to gain reward (Elliott et al, 1997; Forbes et al, 2006; Smoski et al, 2008; Paulus, 2007). In contrast, pathological gamblers are more risk-seeking (Holt et al, 2003). Another aspect of decision making is self-control, or the ability to delay gratification, which is more related to impulsiveness and is impaired in patients with substanceuse disorder (Rogers et al, 1999; Bechara et al, 2002; Paulus, 2007).

Manipulation of serotonin (5-HT) appears to influence decision making. Acute tryptophan depletion (ATD) leads to impulsive choice and impaired decision making related to different magnitudes of gains, in both animals and humans (Rogers et al, 1999, 2003; Mobini et al, 2000; Walderhaug et al, 2007). Furthermore, a recent study showed that tryptophan supplementation significantly decreased loss-aversion (Murphy et al, 2008). Although 
5-HT appears to influence choice involving delayed reinforcement or different magnitudes of gains, it remains unclear whether 5-HT affects choice related to the assessment of probability (Mobini et al, 2000; Anderson et al, 2003; Rogers et al, 2003; Cardinal, 2006), especially at a genetic level.

It has been reported that possession of the less active $\mathrm{S}$ allele of the 5-HT transporter 5HTTLPR polymorphism (SLC6A4 gene short/S-long/L promoter variant) increased sensitivity to the probability of winning in a 'risky-choice task' (Roiser et al, 2006) and promoted disadvantageous choices in the Iowa Gambling Task (IGT) probably due to lack of persistence (Must et al, 2007; Homberg et al, 2008) or to slower learning of advantageous decision making (Jollant et al, 2007). It has also been suggested that $5 H T T L P R$ variations modulate sensitivity to punishment rather than reward, as the LL homozygous individuals are less sensitive to punishment-related information (Blair et al, 2008; Roiser et al, 2009). Jollant et al (2007) showed that genetic variations in the TPH1, TPH2 (tryptophan hydroxylase 1 and 2, respectively), and MAOA (monoamine oxydase A) genes that have been associated with suicide were also associated with poorer performance on the IGT in suicide attempters. However, all of the above-mentioned studies were carried out in small samples (less than 200 subjects) and require confirmation in larger samples.

In this study, the main candidate gene was the TPH2 that codes for the majority of TPH in the human brain (Walther et al, 2003; Zill et al, 2007a). Variations in the TPH2 gene have been repeatedly implicated in major depression disorder (MDD), and in suicidal behavior in MDD patients (Zill et al, 2004a, b; Zhang et al, 2005; Zhou et al, 2005; Lopez et al, 2007a; Haghighi et al, 2008). To cover this gene, we used haplotype tagging SNPs (htSNPs) similar to the previous studies.

As the availability of synaptic 5-HT depends on other serotonergic genes, we also investigated the well-known $5 H T T L P R$ polymorphism and a functional TPH1 gene variant (A218C, rs1800532). A218C has been shown to alter TPH immunoreactivity in postmortem brain samples of both suicide victims and controls (Ono et al, 2002) and has been associated with suicidal behavior ( $\mathrm{Li}$ and $\mathrm{He}, 2006$ ). It has been demonstrated that TPH1 is expressed in several human brain areas, although at lower levels than TPH2 in the raphe (Zill et al, 2007a). Finally, we genotyped for a functional variant in the $5-H T R 1 A$ receptor gene $(C(-1019) G$, rs6295) that modulates the expression of 5-HT1A autoreceptors in raphe cells and that controls 5-HT neuronal firing, and this influence synaptic 5-HT release (Lemonde et al, 2003). This functional polymorphism has previously been associated with depression-, suicide-, and anxiety-related traits (Lemonde et al, 2003; Strobel et al, 2003).

In order to investigate risky decision-making behavior in a large population, we developed a pencil-and-paper probabilistic gambling task administered remotely with questionnaires assessing personality data, current mood, and anxiety symptoms. On the basis of previous literature, we hypothesized that subjects with a self-reported history of depression or with a higher neuroticism, depression and/or anxiety scores would make safer (less risky) choices. Furthermore, we hypothesized that variants in the serotonergic genes and especially in the TPH2 gene that regulates the availability of synaptic 5-HT would influence risky decision making.

\section{MATERIALS AND METHODS}

\section{Participants}

This study was part of the EU funded NewMood (New Molecules for Mood Disorders) research program. We recruited participants aged 18-60 years from Greater Manchester, United Kingdom, through general practices, and a website (http://www.newmood.co.uk); details of our recruitment strategy and responses were published previously (Juhasz et al, 2009). The included participants were of Caucasian European origin and could have a selfreported history of depression or anxiety disorders; we excluded those reporting manic or hypomanic episodes, psychotic symptoms, or obsessive-compulsive disorder (all information based on background self-report questionnaire data). Thus, the population sample in this study consisted of 1188 participants who fulfilled the inclusion criteria, sent back the questionnaire with a completed gambling task and provided DNA. Population details are shown in Table 1. The study was approved by the local Ethics Committees and was carried out in accordance with the Declaration of Helsinki.

\section{Phenotype Assessments}

The NewMood booklet consisted of brief or adapted versions of standard questionnaires that have been validated at a second level of the study in a subset of subjects $(n=142)$ by full versions of the questionnaires and face-toface interviews. The background questionnaire was adapted from a structured self-rating questionnaire (Hunt et al, 1999) that consists of 22 items and collects information about medical history, including personal psychiatric history (particularly depression), family psychiatric history, and socioeconomic background. Impulsivity was measured by the Impulsiveness, Venturesome and Empathy Questionnaire (IVE) Impulsiveness subscale (Eysenck and Eysenck, 1978). For the analysis, a continuous weighted dimension score (sum of item scores divided by the number of items completed) was calculated. The IVE Impulsivity score showed significant correlation with the NEO PI-R (Costa and McCrae, 1992) Impulsiveness (N5) facet score (Pearson's correlation: $R=0.47, p<0.001, n=142$ ) in our validation sample. To assess personality we used the Big Five Inventory (BFI-44) (John et al, 1991), and a continuous weighted dimension score was calculated for Neuroticism. The 53-item Brief Symptom Inventory (BSI) (Derogatis, 1993) was used to measure anxiety symptoms (using the anxiety subscale) and depressive symptoms (using the depression subscale plus additional items); a continuous weighted dimension score was calculated for Depression and Anxiety. Validation data of neuroticism and symptom scores were published previously (Juhasz et al, 2009).

The Recent Negative Life Events questionnaire was based on the validated List of Life Threatening Experiences (LTE) (Brugha et al, 1985; Rijsdijk et al, 2001) and the sum of life event items was used in the analysis. Questions based on the Childhood Trauma Questionnaire (CTQ) (Bernstein et al, 
Table I Population Details for Those Who Fulfilled the Inclusion Criteria for the Study $(n=1 \mid 88)$

\section{Demographics}

Sex

Female

Male

Age (mean \pm SEM)

Education (A levels or higher)

Financial situation

Living comfortably

$672(57 \%)$

Just getting by

Finding it difficult to make ends meet

Personal psychiatric history

Reported depression

Single episode

Recurrent episodes

Reported suicide attempt

Reported anxiety

Reported substance use disorder

Family psychiatric history

Reported depression in immediate blood relatives

$421(35 \%)$

Personality scores

BFI Neuroticism (mean \pm SEM; range I-5)

IVE Impulsiveness (mean \pm SEM; range $0-I$ )

$3.30 \pm 0.03$

$0.36 \pm 0.01$

\author{
Symptom scores \\ BSI Depression (mean \pm SEM; range 0-4) \\ BSI Anxiety (mean \pm SEM; range 0-4)
}

$0.98 \pm 0.03$

$0.92 \pm 0.03$

\author{
Adversities \\ Recent negative life events (mean \pm SEM) \\ Childhood Adversity (mean \pm SEM)
}

$1.27 \pm 0.04$

$3.54 \pm 0.10$

Abbreviations: BFI, Big Five Inventory; BSI, Brief Symptom Inventory; IVE,

Impulsiveness, Venturesome and Empathy Questionnaire.

1994) were used to determine Childhood Adversity related to emotional and physical abuse, and emotional and physical neglect. An additional question asked about parental loss during childhood. The sum of item scores was used in the analysis. Summary scores from the full version of CTQ significantly correlated with scores derived from our short questionnaire (Pearson's correlation: $R=0.75, p<0.001, n=142$ ).

\section{Gambling Task}

This task was derived from that of Rachlin et al (1986). Subjects were presented with a picture of two 'wheel of fortune'-like spinners each with a pointer at the top. Each spinner was divided into a white and a gray segment, and

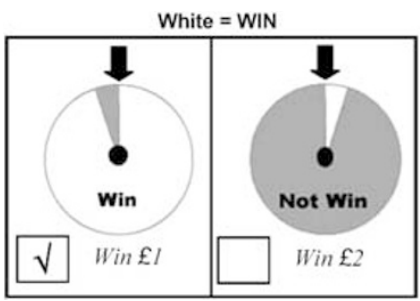

Figure I Decision-making task sample trial.

the subject was told to imagine they would 'win' if the spinner stopped with the white segment under the pointer, but not with the gray (Figure 1). Subjects were instructed to indicate which spinner they would choose to maximize their winnings. Dial ' $A$ ' provided a smaller ( $£ 1)$ but more likely 'win,' whereas dial ' $B$ ' gave a 'win' twice the amount but with a lower probability that was systematically varied. As our reward task was imaginary, subjects did not gain real monetary reward.

The probability of winning on ' $\mathrm{A}$ ' $(\mathrm{pA})$ was set to $p=0.95$, $0.5,0.33$, and 0.25 , whereas probability of winning on ' $\mathrm{B}$ ' was varied from $p=0.80$ to 0.025 but was always lower than $\mathrm{pA}$. As the probability of winning on ' $\mathrm{B}$ ' increased, an indifference point is reached where the participant values both option equally, and may select ' $B$ ' as it offers the potential for a larger 'win.' Odds against winning $(\theta)$ were calculated as $[1 / \mathrm{p}]-1$, giving four $\theta \mathrm{A}$ values $(0.05,1,2,3)$. The odds against winning on ' $B$ ' $(\theta B)$ at which the participant switched from dial ' $A$ ' to dial ' $B$ ' (the indifference point) was calculated for each value of ' $A$ ' by linear interpolation. To assess an individual's overall tendency to take a safer vs more risky choice, we plotted $\theta \mathrm{B}$ against $\theta \mathrm{A}$ and calculated a global area under the curve measure (AUC $\theta)$ using the trapezoid method requiring all four indifference points; a smaller value indicating safer choice. Using AUC $\theta$ gives weight to choices, in which wins are unlikely and is sensitive to how much the individual is willing to take a risk for a greater reward under conditions where both outcomes are uncertain (Ho et al, 1999).

Given the study's constraints, we were not able to determine directly whether participants understood the task and so we included two trials, in which one of the choices was so disadvantageous that its selection was irrational and if chosen the individual was excluded. We also required choices on ' $\mathrm{B}$ ' to follow the same rank order as their corresponding value on ' $\mathrm{A}$ ' (allowing one occurrence of the same value for contiguous choices on ' $B$ '). This excluded participants who, for example, chose a smaller indifference probability on ' $\mathrm{B}$ ' for $p=0.33$ than for $p=0.25$ on 'A.' Using these rules, $87.1 \%(n=1035)$ of participants were included in the final analysis.

From these subjects, 72 completed the computer version of a similar decision-making task and 69 provided calculable data. During this task, the participants were shown two 'wheel of fortune' spinners - A and B - that had a green (win) and a red (lose) segment. Alternative A had a reward of $10 p$; alternative $B$ had a reward of $20 p$ but a lower probability chance of winning compared to A (2 blocks of 41 trials; $\theta \mathrm{A}: \theta=0.00,0.33,1$, and 3 ; $\theta \mathrm{B}$ : from $\theta=0.00$ to $\infty)$. Participants pressed A or B on the keyboard depending on which alternative they preferred. The outcome (which had been decided in a pseudorandom manner) was then 
shown to the subject. The reward was imaginary again, so the subjects did not get real monetary reward. A global AUC $\theta$ was calculated from these data similarly to the paper version of the task. Results from the two tasks showed significant correlation (Pearson's $R=0.30, p=0.012$ ) in this population.

\section{Genotyping}

Buccal mucosa cells were collected from the participants and genomic DNA was extracted according to a previously described method (Freeman et al, 2003).

HaploView software (http://www.broad.mit.edu/personal/ jcbarret/haploview/) was used to identify htSNPs using the confidence interval method (Barrett et al, 2005; Gabriel et al, 2002). The tagging was based on the CEPH (Utah residents with ancestry from northern and western Europe) data that were available at the International HapMap Project Phase I. June 2005 release (http://www.hapmap.org), thus SNPs (functional or tagging) that were identified later were not included in this study. We also genotyped a further three functionally relevant serotonergic polymorphisms: 5HTTLPR, rs6295, and rs1800532.

The chosen SNPs were genotyped using the Sequenom $\mathbb{R}$ MassARRAY technology (Sequenom, San Diego, http:// www.sequenom.com) using $25 \mathrm{ng}$ of DNA. Determination of the $5 H T T L P R$ genotype was performed in a Thermo-Fast $\mathbb{R}$ 384 PCR plate (ABgene Ltd, UK) on a PTC-220 Dyad TM thermocycler (Bio-Rad, Hercules, CA). Polymerase chain reaction products were analyzed using an ABI3100 Genetic Analyzer and GeneScan analysis software (Applied Biosystems, Netherlands). Genotyping was performed blinded with regard to phenotype. All laboratory work was performed under the ISO 9001:2000 quality management requirements. The genotyping methods in more details can be seen in Supplementary Document 1.

\section{Statistical Analysis}

Statistical analyses were performed using SPSS for Windows Statistical Analysis Software, Version 15.0. A p-value of $<0.05$ was adopted for all statistical testing, and all reported $p$-values were two-tailed.

We used the HaploView program to explore the haplotype structure of TPH2 gene (Gabriel et al, 2002; Barrett et al, 2005); Quanto 1.2 version (http://hydra.usc.edu/gxe) to calculate the power of the recruited populations; and PLINK v1.06 (http://pngu.mgh.harvard.edu/purcell/plink/) for testing association of different genetic models (dominant, recessive, and additive; linear regression model covariation with age and sex), interactions between SNPs (epistasis) and with sex, and for calculating Hardy-Weinberg analysis.

Haplotype analyses were performed with HelixTree ${ }^{\mathrm{TM}}$ 6.4.1 (Golden Helix, USA) using haplotype trend regression. Only haplotypes with a frequency greater than $5 \%$ were used in the linear regression analysis, similar to the method described previously (Juhasz et al, 2009). In all cases, data were adjusted for age and sex. To reduce the influence of multiple testing, we used a permutation test, randomly grouping the sample 10000 times.

For both single-marker association and haplotypic association analyses, we used false discovery rate calculation at a level of 5\% (FDR; Qvalue: http://genomics.princeton. edu/storeylab/qvalue/) to adjust $p$-values according to the number of hypothesis tested (Storey and Tibshirani, 2003). We report $q$-value, which is a measure of significance of each test of many tests performed simultaneously.

\section{RESULTS}

\section{Decision-Making Task}

Women were less likely to make risky decisions than men, represented by lower AUC $\theta$ values $(\mathrm{F}=9.38, \mathrm{df}=1,1032$, $p=0.002$; AUC $\theta$ mean \pm SEM after covariation for age: males - 10.42 \pm 0.36 , females - $9.09 \pm 0.24$; explained variance $0.9 \%)$. Subjects with reported depression were also less likely to make risky decisions $(\mathrm{F}=4.83, \mathrm{df}=1,1031, p=0.028$; $\mathrm{AUC} \theta$ mean \pm SEM after covariation for age and gender: no depression-9.99 \pm 0.30 , depression-9.09 \pm 0.28$)$. Higher neuroticism (Pearson's correlation $R=-0.13, p<0.001$ ), depression (Pearson correlation $R=-0.13, p<0.001$ ), and anxiety (Pearson's correlation $R=-0.13, p<0.001$ ) scores were also associated with risk aversion. These factors explained a further $1.6 \%$ variance in risk-taking behavior. However, impulsivity measured by IVE and risk taking measured by our task were independent of each other (Pearson's correlation $R=-0.02, p=0.233$ ). Both Childhood Adversity (Pearson's $R=-0.06, p=0.039)$ and Recent Negative Life Events (Pearson's $R=-0.06, p=0.042$ ) significantly correlated with less risk taking, but after correction for depressive and anxiety symptoms this effect became nonsignificant (Childhood Adversity: Pearson's $R=-0.02, p=0.629$; Recent Negative Life Events: Pearson's $R=-0.03, p=0.344$ ).

After covariation for age and gender, there were no significant difference in neuroticism $(p=0.45)$, impulsivity $(p=0.20)$, symptom scores (depression, $p=0.80$; anxiety, $p=0.82)$ or education level $(p=0.24)$ between those who did not provide consistent task results $(n=153)$ and who did $(n=1035)$.

Using the computer version of the decision-making task, females were less likely to make risky decisions $(\mathrm{F}=3.78, \mathrm{df}=1,66, p=0.056 ; \mathrm{AUC} \theta$ mean $\pm \mathrm{SEM}$ after covariation for age: males $(n=30)-11.17 \pm 0.67$, females $(n=39)-9.44 \pm 0.59$; explained variance $5.4 \%)$, although this effect missed the significance threshold. We did not find a significant difference between those with and without lifetime major depressive disorder according to SCID $(\mathrm{F}=0.91, \mathrm{df}=1,64, p=0.344 ;$ AUC $\theta$ mean \pm SEM after covariation for age and gender: no psychiatric disorder $(n=28)-9.66 \pm 0.71$, lifetime $\operatorname{MDD}(n=40)-$ $10.56 \pm 0.59)$. However, subjects with low symptom scores (MADRS $\leqslant 7 ; n=53$ ) tended to make more risky decisions than those who had high symptom scores (MADRS $>7$, $n=16 ; \mathrm{F}=3.42, \mathrm{df}=1,65, p=0.069 ;$ AUC $\theta$ mean $\pm \mathrm{SEM}$ after covariation for age and gender: low symptom score $-10.65 \pm 0.50$, high symptom score $-8.68 \pm 0.93$; explained variance $2.8 \%$ ).

\section{Genotyping Results}

HaploView analysis of the TPH2 gene-based on the HapMap Project Phase I. (June 2005) release CEPH population data-resulted in seven htSNPs that were 
Table 2 Summary of the Genotyped SNPs

\begin{tabular}{|c|c|c|c|c|c|c|c|}
\hline \multirow{2}{*}{ SNP no. } & \multirow{2}{*}{ DbSNPa no. } & \multirow{2}{*}{ Position $^{\mathrm{b}}$} & \multirow{2}{*}{ Location } & \multirow{2}{*}{ Allele (minor/major) } & \multicolumn{2}{|c|}{ Manchester } & \multirow{2}{*}{$\begin{array}{c}\text { CEPH }^{c} \\
\text { MAF (\%) }\end{array}$} \\
\hline & & & & & MAF (\%) & HWE $p$ & \\
\hline \multicolumn{8}{|c|}{$\mathrm{TPH} 2(\mathrm{Chr}$ l2q21.1) } \\
\hline I & rs| 843809 & 70634965 & Intron5 & $\mathrm{G} / \mathrm{T}$ & 16 & 0.118 & 12 \\
\hline 2 & rs|386493 & $7064 \mid 446$ & Intron5 & $\mathrm{T} / \mathrm{C}$ & 18 & 0.420 & 15 \\
\hline 5 & Rs 1352250 & 7068405 I & Intron8 & $A / G$ & 43 & 0.856 & 38 \\
\hline 6 & rs| 487275 & 70696559 & Intron8 & $\mathrm{G} / \mathrm{T}$ & 27 & 0.759 & 25 \\
\hline 7 & rs|386485 & 70698634 & Intron8 & C/A & 34 & 0.690 & 30 \\
\hline \multicolumn{8}{|c|}{ SLC6A4 (Chrl7qII.I-q/2) } \\
\hline 9 & rs6295 & 63294321 & Promoter & $\mathrm{G} / \mathrm{C}$ & 48 & 0.125 & $54^{e}$ \\
\hline \multicolumn{8}{|c|}{ TPHI (Chrl Ip/5.3-p/4) } \\
\hline 10 & rs| 800532 & | 8004392 & Intron5 & $\mathrm{A} / \mathrm{C}$ & 40 & 0.195 & 40 \\
\hline
\end{tabular}

HWE, Hardy-Weinberg equilibrium; MAF, minor allele frequency.

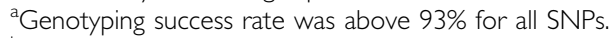

bPosition according to National Center for Biotechnology Information (NCBI, March 2007).

${ }^{\mathrm{C}} \mathrm{CEPH}$ : collection consists of 30 mother-father-child trios with Northern and Western Europe ancestry, data based on the HapMap Project Phase II. (November 2008) release.

${ }^{\mathrm{d} N o}$ CEPH data, based on Lesch et al (1996).

${ }^{\mathrm{e}} \mathrm{No}$ CEPH data, based on Strobel et al (2003).

genotyped in our study. Details about the TPH2 htSNPs and the genotyped three functional serotonergic polymorphisms can be seen in Table 2. Although no genomic control by random marker genotyping was performed in the study population, we attempted to reduce ethnic variation and stratification effects by including only independent Caucasian subjects of European origin in the analysis. Indeed, all of the genotyped polymorphisms were in Hardy-Weinberg equilibrium both in the total population and separately for those who reported depression and who did not (data not shown). TPH2 linkage disequilibrium (LD) block structure is similar in our population and in the $\mathrm{CEPH}$ population (data from the HapMap Project Phase II. (November 2008) release; see Figure 2). Although in this study we did not genotype functional SNPs in the TPH2 gene, we do show the LD data between our htSNPs and rs4570625 (-703G/A) (Chen et al, 2008) and rs7305115 (Lim et al, 2007) in the CEPH population in order to interpret our results. There are no available data in the CEPH population about other functional SNPs ( $r s 11178997:-473 T / A$; $r s 11178998: 90 A / G$ ) (Chen et al, 2008; Lin et al, 2007; Scheuch et al, 2007).

\section{Single-Marker Associations}

We found significant association of the AUC $\theta$ and TPH2 htSNPs, and after FDR correction the association remained significant for $r s 6582078$ and $r s 1352250$ (Table 3). The minor alleles were positively associated with increased risk

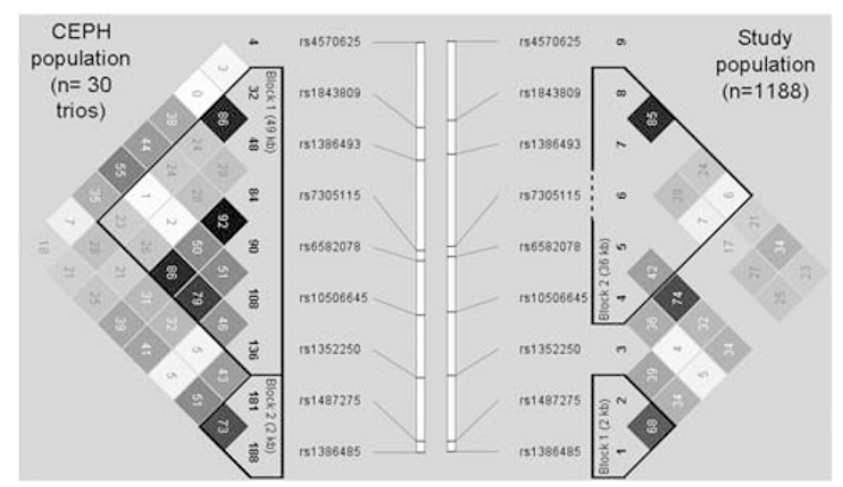

Figure 2 Linkage disequilibrium (LD) $R^{2}$ data of the TPH2 gene in the $\mathrm{CEPH}$ population (HapMap Project Phase II. November 2008 release) and in our study. Blocks of LD have been identified on the basis of the method published by Gabriel et al (2002) using Haploview program.

taking in all htSNPs. There was no significant markerspecific association between 5HTTLPR, rs6295 or rs 1800532 and risk taking. None of the SNPs showed association with symptom or personality scores after correction for multiple testing (Supplementary Table S1).

Because AUC $\theta$ showed significant difference between males and females, we tested the interaction of SNPs and sex. None of the SNPs showed significant interaction with sex on risk-taking AUC $\theta$ after correction for multiple testing (Supplementary Table S2a). Furthermore, TPH2 


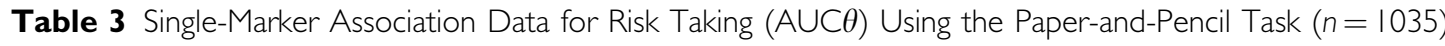

\begin{tabular}{|c|c|c|c|c|c|c|c|c|c|c|c|}
\hline No. & SNP & Al & Test & Beta & SE & 95\% Cl Lower & 95\% Cl Upper & $t$ & Cohen's d & $p$-value & FDR $q$ \\
\hline \multirow[t]{3}{*}{ I } & rs 1843809 & $G$ & ADD & 0.883 & 0.411 & 0.077 & 1.690 & 2.148 & 0.14 & 0.032 & 0.239 \\
\hline & & G & DOM & 0.987 & 0.454 & 0.097 & 1.877 & 2.173 & 0.14 & 0.030 & 0.239 \\
\hline & & G & REC & 1.004 & 1.520 & -1.974 & 3.982 & 0.661 & 0.04 & 0.509 & 0.839 \\
\hline \multirow[t]{2}{*}{2} & rs|386493 & $\mathrm{T}$ & ADD & 0.850 & 0.388 & 0.090 & 1.610 & 2.193 & 0.14 & 0.029 & 0.239 \\
\hline & & $T$ & DOM & 0.867 & 0.440 & 0.004 & 1.729 & 1.970 & 0.12 & 0.049 & 0.318 \\
\hline \multirow{2}{*}{3} & & G & DOM & 1.272 & 0.445 & 0.399 & 2.145 & 2.855 & 0.18 & 0.004 & 0.119 \\
\hline & & G & REC & 1.926 & 0.543 & 0.861 & 2.991 & 3.545 & 0.22 & 0.0004 & 0.014 \\
\hline \multirow[t]{2}{*}{4} & rs 10506645 & $\mathrm{~T}$ & ADD & 0.747 & 0.352 & 0.056 & 1.438 & 2.119 & 0.13 & 0.034 & 0.239 \\
\hline & & $\mathrm{T}$ & DOM & 0.618 & 0.422 & -0.209 & 1.446 & 1.465 & 0.09 & 0.143 & 0.589 \\
\hline \multirow[t]{3}{*}{6} & rs| 487275 & G & ADD & 0.804 & 0.342 & 0.134 & 1.474 & 2.352 & 0.15 & 0.019 & 0.239 \\
\hline & & G & DOM & 0.947 & 0.426 & 0.112 & 1.781 & 2.224 & 0.14 & 0.026 & 0.239 \\
\hline & & $G$ & REC & 1.169 & 0.844 & -0.484 & 2.822 & 1.386 & 0.09 & 0.166 & 0.627 \\
\hline \multirow[t]{3}{*}{7} & rs|386485 & $C$ & ADD & 0.837 & 0.316 & 0.217 & 1.456 & 2.648 & 0.17 & 0.008 & 0.160 \\
\hline & & C & DOM & 0.904 & 0.427 & 0.068 & $1.74 \mid$ & 2.118 & 0.14 & 0.034 & 0.239 \\
\hline & & $C$ & REC & 1.496 & 0.663 & 0.196 & 2.796 & 2.255 & 0.14 & 0.024 & 0.239 \\
\hline \multirow[t]{3}{*}{8} & 5HTTLPR & A & ADD & -0.014 & 0.293 & -0.588 & 0.560 & -0.047 & 0.00 & 0.963 & 0.841 \\
\hline & & A & DOM & 0.297 & 0.442 & -0.569 & 1.163 & 0.672 & 0.04 & 0.502 & 0.772 \\
\hline & & $A$ & REC & -0.459 & 0.522 & -1.483 & 0.565 & -0.879 & -0.06 & 0.380 & 0.688 \\
\hline 9 & rs6295 & G & ADD & -0.037 & 0.283 & -0.592 & 0.517 & -0.132 & -0.01 & 0.895 & 0.833 \\
\hline
\end{tabular}

In all calculations, age and sex were covariates. $t$, $t$-test statistics; Cohen's $d$, standardized effect sizes; $p$, uncorrected significance value; FDR $q$, false discovery rate significance value.

The significance values $<0.05$ are indicated in bold.

htSNPs did not show significant interaction (epistasis) with 5HTTLPR, rs6295, or rs1800532 on AUC $\theta$ (Supplementary Table S2b).

Assuming a continuous trait such as AUC $\theta$ data, using an independent-individual study design and assuming an additive linear model relating the phenotype to genotype, we had a $90-93 \%$ power in our population $(N=1035$ and $N=1188$ ) to detect a polymorphism (with a minor allele frequency $\geqslant 10 \%$ ) that could explain $1 \%$ of the variance of the trait at the 5\% two-tailed significance level. To detect gene $\times$ sex interaction in the same model as above and assuming that sex explains 5\% variance, we had a $91-95 \%$ power in our population. Furthermore, for epistasis we had a $90-94 \%$ power in our population if the other gene also explains $1 \%$ variance and the gene $\times$ gene interaction explains further $1 \%$ variance.

Using the computer task data, single-marker associations showed similar results with higher effect sizes to the penciland-paper task results (see Table 4).

\section{TPH2 Haplotype Association With AUCO}

The overall genetic effect of TPH2 haplotypes for the AUC $\theta$ data was significant and remained significant after permutation tests and correction for multiple testing (Table 5). The TPH 2 haplotypes explained $1.9 \%$ variance in risk taking. The haplotypic association did not change after adding BSI Depression and Anxiety scores (permutated FDR corrected $q=0.018$ ) or BFI neuroticism scores (permutated FDR corrected $p=0.018$ ) as covariates in the analysis. These results suggest that there is a genetic effect on this measure of decision making, which is independent of current mood and anxiety state or neuroticism. Indeed, the TPH2 gene showed no significant haplotypic association with BSI depression (permutated FDR corrected $q=0.337$ ), BSI anxiety (permutated FDR corrected $q=0.172$ ), BFI neuroticism (permutated FDR corrected $q=$ 0.314 ), or IVE impulsivity (permutated FDR corrected $q=0.174)$ scores. 
Table 4 Single-Marker Association Data For Risk Taking (AUC $\theta)$ Using the Computer Task $(n=69)$

\begin{tabular}{|c|c|c|c|c|c|c|c|c|c|c|}
\hline No. & SNP & Al & Test & Beta & SE & 95\% CI Lower & 95\% CI Upper & $t$ & Cohen's d & $p$-value \\
\hline \multirow[t]{3}{*}{1} & rs|843809 & G & ADD & 1.297 & 0.801 & -0.273 & 2.867 & 1.619 & 0.41 & 0.111 \\
\hline & & G & DOM & $1.34 \mid$ & 0.863 & -0.350 & 3.032 & 1.555 & 0.39 & 0.125 \\
\hline & & G & REC & 2.372 & 3.395 & -4.283 & 9.027 & 0.699 & 0.18 & 0.488 \\
\hline \multirow[t]{2}{*}{2} & rs|386493 & $\mathrm{T}$ & ADD & 1.138 & 0.705 & -0.243 & 2.520 & 1.616 & 0.41 & 0.111 \\
\hline & & $\mathrm{T}$ & DOM & 1.033 & 0.847 & -0.627 & 2.693 & 1.220 & 0.31 & 0.227 \\
\hline \multirow{2}{*}{3} & & G & DOM & 2.012 & 1.111 & -0.166 & 4.191 & 1.811 & 0.45 & 0.075 \\
\hline & & G & REC & 0.649 & 1.123 & -1.553 & 2.850 & 0.577 & 0.14 & 0.566 \\
\hline \multirow[t]{2}{*}{4} & rs 10506645 & $\mathrm{~T}$ & ADD & -0.107 & 0.762 & -1.601 & 1.386 & -0.141 & -0.04 & 0.889 \\
\hline & & $\mathrm{T}$ & DOM & 0.011 & 0.972 & -1.894 & 1.917 & 0.012 & 0.00 & 0.991 \\
\hline \multirow[t]{3}{*}{6} & rs|487275 & G & ADD & 1.392 & 0.721 & -0.020 & 2.805 & 1.932 & 0.49 & 0.058 \\
\hline & & G & DOM & 1.913 & 0.893 & 0.163 & 3.662 & 2.143 & 0.54 & 0.036 \\
\hline & & G & REC & 0.939 & 1.784 & -2.558 & 4.436 & 0.526 & 0.13 & 0.601 \\
\hline \multirow[t]{3}{*}{7} & rs|386485 & C & ADD & 1.642 & 0.565 & 0.535 & 2.750 & 2.906 & 0.73 & 0.005 \\
\hline & & C & DOM & 2.109 & 0.819 & 0.503 & 3.715 & 2.574 & 0.65 & 0.013 \\
\hline & & C & REC & 2.275 & 1.125 & 0.070 & 4.479 & 2.022 & 0.51 & 0.048 \\
\hline \multirow[t]{3}{*}{8} & 5HTTLPR & A & ADD & -0.040 & 0.685 & -1.383 & 1.302 & -0.059 & -0.01 & 0.953 \\
\hline & & A & DOM & -0.379 & $1.07 \mid$ & -2.477 & 1.720 & -0.354 & -0.09 & 0.725 \\
\hline & & A & REC & 0.333 & 1.168 & -1.957 & 2.623 & 0.285 & 0.07 & 0.777 \\
\hline 9 & rs6295 & C & ADD & -0.909 & 0.766 & -2.411 & 0.593 & -1.186 & -0.30 & 0.240 \\
\hline
\end{tabular}

In all calculations, age and sex were covariates. $t$, $t$-test statistics; Cohen's $d$, standardized effect sizes; $p$, uncorrected significance value. The significance values $<0.05$ are indicated in bold.

Table 5 TPH2 Haplotypic Regression Results For Risk Taking Measured by AUC $\theta$

\begin{tabular}{|c|c|c|c|c|c|c|c|}
\hline No. & Haplotypes & Frequencies (\%) & Beta & SE & $t$ & $p$-value & FDR q \\
\hline I & T,C,T,C,G,T,A & 49 & -1.239 & 0.551 & -2.248 & 0.025 & 0.022 \\
\hline 2 & $\mathrm{G}, \mathrm{T}, \mathrm{G}, \mathrm{C}, \mathrm{A}, \mathrm{G}, \mathrm{C}$ & 14 & 3.194 & 1.855 & 1.722 & 0.085 & 0.058 \\
\hline 4 & T,C,G,T,A,G,C & 10 & 0.228 & 1.913 & 0.119 & 0.905 & 0.348 \\
\hline 5 & Rare haplotypes & 16 & \multicolumn{5}{|c|}{ Left out regressor } \\
\hline
\end{tabular}

Age and sex were covariate in the calculations, and the order of the htSNPs in the haplotypes corresponds to the SNP order in Table 2. $t$, $t$-test statistics; $p$, uncorrected significance value; FDR q, false discovery rate significance value.

The most common haplotype T,C,T,C,G,T,A was found in $49 \%$ of study participants. Beta values suggest that carriers were relatively risk avoidant and made significantly less risky decisions than the other haplotype carriers (permutated FDR corrected $q=0.022$ ).
This effect was also significant for the risk-taking AUC $\theta$ calculated from the computer task $(\beta=-2.619$, $\mathrm{SE}=1.271, \quad t=-2.06$, permutated $p=0.044$, explained variance $5.9 \%, n=69$, frequency of the T,C,T,C,G,T,A haplotype $=45 \%)$. 


\section{DISCUSSION}

Using haplotypic association, we found significant differences in risk-taking behavior on a performance gambling task between the most prevalent haplotype and the other haplotypes of the TPH2 gene. Subjects carrying the most prevalent T,C,T,C,G,T,A haplotype had lower AUC $\theta$ parameters suggesting that they are less likely to make risky decisions. Thus, our finding implies involvement of the serotonergic system, namely, the TPH2 gene, in decision making through altering willingness to take risks for reward. In addition, we tested whether differences in risktaking behavior measured by our task were influenced by other serotonergic genes. We genotyped a further three serotonergic functional polymorphisms (5HTTLPR in serotonin transporter, rs6295 in 5HTR1A receptor, and rs1800532 in TPH1 genes) but could not demonstrate significant main effects of these polymorphisms or interaction with the TPH2 htSNPs on risk taking. However, we could not exclude that these genes modulate other aspects of decision making that were not measured by our task, such as punishment- or feedback-related processing, as previous studies reported (Jollant et al, 2007; Must et al, 2007; Blair et al, 2008; Homberg et al, 2008).

Accumulating evidence suggest that the more common allele/haplotype variants in the $\mathrm{TPH} 2$ gene are associated with lower cerebrospinal fluid 5-hydroxyindoleacetic acid concentrations (Zhou et al, 2005) and with decreased TPH2 mRNA expression (Chen et al, 2008; Chen and Miller, 2008; Haghighi et al, 2008; Lim et al, 2007). Thus, a considerable proportion of the population, who carry the wild-type (most ancient) variation of the TPH2 gene, express TPH2 at low level that results in decreased serotonin availability at the raphe nucleus and its projections, and also show risk aversion on the basis of our results. This situation is somewhat parallel to the ATD, which has been shown to reduce 5-HT levels to a functionally significant degree. However, human studies have not demonstrated a consistent effect of reducing 5-HT function using dietary ATD on probabilistic choice behavior: Rogers et al (1999) reported that after ATD subjects chose the most likely option less often, while Talbot et al (2006) demonstrated the opposite and our group could not find any significant difference (Anderson et al, 2003). The most plausible explanation for these discrepancies is that these studies used different tasks to measure risk taking and probably were not adequately powered to detect the effect of ATD on probabilistic choice. Indeed, on the basis of our results, variability in serotonin synthesis caused by the TPH2 gene only explained $1.9 \%$ (paper-and-pencil task) $-5.9 \%$ (computer task) of the variance in risk taking. Another possible explanation is that the genetic make-up of the participants interfered with the effect of the ATD, as has been suggested in relation of the 5HTTLPR variant (Blair et al, 2008).

Our results suggest that there is a biological distinction to be made between impulsive and safe/risky decision making as measured with our task. Although impulsivity has usually been associated with an increased tendency to take risks, such as in DSM-IV-defined impulse control disorders (American Psychiatric Association, 2000), it only appears to predict some risky behaviors, whereas others are more linked to neuroticism and extraversion (Cooper et al, 2000). Impulsivity may be more related to inability to delay gratification and Crean et al (2000) demonstrated that delay discounting has a closer relationship to self-reported impulsivity measurements than probability discounting. Low 5-HT function has been associated with increased impulsivity (eg Dolan et al, 2001) in contrast to our finding that the common TPH2 variant, likely to be associated with reduced 5-HT function, is associated with risk aversion rather than risk taking when faced with a probabilistic choice. This highlights the complex role of 5-HT in behavior and mood and the need to carefully specify neuropsychological function when investigating the neurobiology of behavior.

Our task has face validity when considered in relation to mood in our subjects. Depression is characterized by reduced motivation to obtain reward and reduced enjoyment of it (Elliott et al, 1997; Forbes et al, 2006), whereas anxiety is associated with intolerance of uncertainty (Paulus et al, 2003; Paulus, 2007). Hence, subjects with depression and anxiety, which are frequently comorbid disorders, would be expected to be less motivated, indeed averse, to take more risks for a greater uncertain reward compared to controls (Smoski et al, 2008). This is consistent with the findings in our sample, in which higher depression, anxiety, and neuroticism ratings were associated with a lower tendency to take risks (AUC $\theta$ ) and explained 1.6\%-2.8\% variance in this phenotype. However, our study also demonstrated that the effect of TPH2 on risk taking is independent of depression and anxiety symptom scores and also independent of neuroticism, thus indicating a separate mode of action. Furthermore, we could not demonstrate any association between haplotype variants of the TPH2 gene and BSI depression, BSI anxiety, BFI neuroticism, or IVE impulsiveness scores. This is in agreement with recent studies which failed to find any association between the TPH2 gene and depression/suicidal behavior (Mann et al, 2008; Must et al, 2007; Zill et al, 2007b; De Luca et al, 2006; Lopez et al, 2007b), but in contrast to earlier findings reporting such an involvement (Zill et al, 2004a, b; Zhou et al, 2005; Van Den Bogaert et al, 2006; Haghighi et al, 2008; Lopez et al, 2007a; Ke et al, 2006). Therefore, the interpretation we favor is that the variations in the TPH2 gene might be linked to an endophenotype influencing risktaking behavior that could be an additive or in some cases a vulnerability factor, for psychiatric disorders, for example, affective disorders or disturbed mood in impulse control or substance misuse disorders. As previous studies have investigated severe clinical populations (hospitalized major depressive patients, completed suicides with MDD), it is likely they represented extreme cases in which TPH2 haplotypes may have contributed to the phenotypic picture through altered risk-taking behavior, potentially leading to patient selection bias and an apparent association between depression/suicide and TPH2 haplotypes. A modulatory rather than causative role of serotonin and $\mathrm{TPH} 2$ in psychiatric disorders was suggested by TPH2 and TPH1/ TPH2 double knockout (KO) animal data. TPH2 KO animals did not show apparent neuronal developmental abnormalities (Gutknecht et al, 2008), and even double KOs showed only mildly increased anxiety-like behavior (Savelieva et al, 2008). 
The main strength of our study is that this is the first attempt to investigate the role of serotonergic genes in decision-making behavior in a large sample using a performance measure plus personality and symptom questionnaires. Furthermore, we were able to validate the questionnaire findings in a subgroup using a more extensive assessment including questionnaire and observer ratings and a computerized task. We have also recently reported that there is no difference in risky choice behavior between receiving real and hypothetical rewards when using this computerized task (Hinvest and Anderson, 2009). The findings in the subgroup largely replicated the findings in the main sample. The computerized task showed only a modest, although significant, correlation with the penciland-paper task, which is likely to be explained by methodological differences (amount to be won and different probabilities) and sampling error, as each indifference point was only assessed on one occasion in the pencil-and-paper task but on two occasions in the computerized version. Differences in genetic effect sizes (small effect sizes for the paper-and-pencil task and medium-large effect sizes for the computerized task, see Tables 3 and 4) probably are related to these methodological differences as the computerized task is likely to be a more sensitive tool to measure decision-making differences.

Our TPH2 finding has limitations, as we did not genotype recently identified functional variants in this gene. Therefore, we compared the LD pattern in our population and in the CEPH population, using our htSNPs (based on the International HapMap Project Phase I. June 2005 release) and recently genotyped functional SNPs (CEPH population, HapMap Project Phase II. November 2008 release), to interpret our results (Figure 2). We can conclude that our study satisfactorily captured the possible influence of functional variants that resides in the region around introns 5-8 and previously have been implicated in regulation of splicing, and therefore might influence the level of the active enzyme (Haghighi et al, 2008; Lim et al, 2007). Nonetheless, we have limited information about the promoter region of the $\mathrm{TPH} 2$ gene, which exhibits only moderate LD with our two most significant SNPs ( $r 6582078$ and $r s 1352250$ ) (Figure 2b) (Chen et al, 2008; Lin et al, 2007; Scheuch et al, 2007). Associations have been demonstrated with the TPH2 promoter region and traits related to emotional dysregulation, such as harm avoidance (Gutknecht et al, 2007; Reuter et al, 2007; Strobel et al, 2007) and amygdala activation during emotional processing (Brown et al, 2005; Canli et al, 2005). However, we did not find any association between haplotype variants of the TPH2 gene and depression, anxiety, neuroticism, or impulsiveness scores that might be influenced by functional variations in the TPH2 promoter region. Using denser htSNP cover on the full length of the TPH2 gene and including independent replication populations into the study would help us to answer these questions and support our new findings. The lack of independent replication population in this study is a major limitation and warrants further research in this field.

We genotyped functional polymorphisms in other serotonergic genes but could not replicate previous positive findings (Ono et al, 2002; Lesch et al, 1996; Lemonde et al, 2003), despite our study being sufficiently powered to identify genetic effect that explain $1 \%$ variance in personality and symptom scores (Juhasz et al, 2009). Our findings are however consistent with the recent scientific literature, as a large meta-analysis showed that several studies have failed to show association between anxiety-related traits and $5 H T T L P R$, except neuroticism measured by NEO (Munafo et al, 2009): it has been argued that genetic effects on neuroticism might be complex and smaller than $1 \%$ per genetic variants (Shifman et al, 2008).

In conclusion, our study is the first to support a role for the $\mathrm{TPH} 2$ gene as a trait factor in determining risky choice behavior as tested in a probabilistic choice task. We also demonstrated that risk-taking behavior is modified by statedependent elements, such depression and anxiety, independently of the TPH2 gene effect. Thus, this biological marker may contribute to the expression of psychiatric phenotypes and possibly to a vulnerability to develop specific disorders. Our results support the importance of identifying quantitative traits, biological markers, or endophenotypes that might be more informative for genetic studies than heterogenic, complex disorders such as depression or complex traits such as impulsivity.

\section{ACKNOWLEDGEMENTS}

We are grateful to Heaton Mersey Medical Practice and Cheadle Medical Practice for their assistance in the recruitment and to Dr Xiayi Ke for statistical advices. This study was supported by the Sixth Framework Program of the EU, NewMood, LSHM-CT-2004-503474 and ETT 3180412009. This work was presented in preliminary form at the BAP 2007 Summer Meeting of the British Association for Psychopharmacology, Harrogate, UK, 22-25 July 2007, and at the 20th ECNP Congress, Vienna, Austria, 13-17 October 2007.

\section{DISCLOSURE}

The authors declare that, except for income received from their primary employer, no financial support or compensation has been received from any individual or corporate entity over the past 3 years for research or professional service and there are no personal financial holdings that could be perceived as constituting a potential conflict of interest.

\section{REFERENCES}

American Psychiatric Association (2000). Diagnostic and Statistical Manual of Mental Disorders 4th edn. Text Revision (DSMIV-TR) American Psychiatric Association: Arlington, VA.

Anderson IM, Richell RA, Bradshaw CM (2003). The effect of acute tryptophan depletion on probabilistic choice. J Psychopharmacol 17: 3-7.

Barrett JC, Fry B, Maller J, Daly MJ (2005). Haploview: analysis and visualization of LD and haplotype maps. Bioinformatics 21: 263-265.

Bechara A, Dolan S, Hindes A (2002). Decision-making and addiction (part II): myopia for the future or hypersensitivity to reward? Neuropsychologia 40: 1690-1705.

Bernstein DP, Fink L, Handelsman L, Foote J, Lovejoy M, Wenzel $\mathrm{K}$ et al (1994). Initial reliability and validity of a new retrospective measure of child abuse and neglect. $A m \mathrm{~J}$ Psychiatry 151: 1132-1136. 
Blair KS, Finger E, Marsh AA, Morton J, Mondillo K, Buzas B et al (2008). The role of 5-HTTLPR in choosing the lesser of two evils, the better of two goods: examining the impact of 5-HTTLPR genotype and tryptophan depletion in object choice. Psychopharmacology (Berl) 196: 29-38.

Brown SM, Peet E, Manuck SB, Williamson DE, Dahl RE, Ferrell RE et al (2005). A regulatory variant of the human tryptophan hydroxylase- 2 gene biases amygdala reactivity. Mol Psychiatry 10: $884-888,805$.

Brugha T, Bebbington P, Tennant C, Hurry J (1985). The List of Threatening Experiences: a subset of 12 life event categories with considerable long-term contextual threat. Psychol Med 15: 189-194.

Canli T, Congdon E, Gutknecht L, Constable RT, Lesch KP (2005). Amygdala responsiveness is modulated by tryptophan hydroxylase-2 gene variation. J Neural Transm 112: 1479-1485.

Cardinal RN (2006). Neural systems implicated in delayed and probabilistic reinforcement. Neural Netw 19: 1277-1301.

Chen GL, Miller GM (2008). Rhesus monkey tryptophan hydroxylase-2 coding region haplotypes affect mRNA stability. Neuroscience 155: 485-491.

Chen GL, Vallender EJ, Miller GM (2008). Functional characterization of the human $\mathrm{TPH} 25^{\prime}$ regulatory region: untranslated region and polymorphisms modulate gene expression in vitro. Hum Genet 122: 645-657.

Cooper ML, Agocha VB, Sheldon MS (2000). A motivational perspective on risky behaviors: the role of personality and affect regulatory processes. J Pers 68: 1059-1088.

Costa Jr PT, McCrae RR (1992). Revised NEO Personality Inventory (NEO-PI-R) and NEO Five-Factor Inventory (NEO-FFI) Professional Manual. Psychological Assessment Resources: Odessa, FL.

Crean JP, de Wit H, Richards JB (2000). Reward discounting as a measure of impulsive behavior in a psychiatric outpatient population. Exp Clin Psychopharmacol 8: 155-162.

De Luca V, Hlousek D, Likhodi O, Van Tol HH, Kennedy JL, Wong $\mathrm{AH}$ (2006). The interaction between TPH2 promoter haplotypes and clinical-demographic risk factors in suicide victims with major psychoses. Genes Brain Behav 5: 107-110.

Derogatis LR (1993). BSI: Brief Symptom Inventory: Administration, Scoring, and Procedures Manual. National Computer Systems Pearson Inc.: Minneapolis.

Dolan M, Anderson IM, Deakin JF (2001). Relationship between 5-HT function and impulsivity and aggression in male offenders with personality disorders. Br J Psychiatry 178: 352-359.

Elliott R, Deakin B (2005). Role of the orbitofrontal cortex in reinforcement processing and inhibitory control: evidence from functional magnetic resonance imaging studies in healthy human subjects. Int Rev Neurobiol 65: 89-116.

Elliott R, Sahakian BJ, Herrod JJ, Robbins TW, Paykel ES (1997). Abnormal response to negative feedback in unipolar depression: evidence for a diagnosis specific impairment. J Neurol Neurosurg Psychiatry 63: 74-82.

Eysenck SB, Eysenck HJ (1978). Impulsiveness and venturesomeness: their position in a dimensional system of personality description. Psychol Rep 43: 1247-1255.

Forbes EE, Christopher MJ, Siegle GJ, Ladouceur CD, Ryan ND, Carter CS et al (2006). Reward-related decision-making in pediatric major depressive disorder: an fMRI study. J Child Psychol Psychiatry 47: 1031-1040.

Freeman B, Smith N, Curtis C, Huckett L, Mill J, Craig IW (2003). DNA from buccal swabs recruited by mail: evaluation of storage effects on long-term stability and suitability for multiplex polymerase chain reaction genotyping. Behav Genet 33: 67-72.

Gabriel SB, Schaffner SF, Nguyen H, Moore JM, Roy J, Blumenstiel $B$ et al (2002). The structure of haplotype blocks in the human genome. Science 296: 2225-2229.

Gutknecht L, Jacob C, Strobel A, Kriegebaum C, Muller J, Zeng Y et al (2007). Tryptophan hydroxylase-2 gene variation influences personality traits and disorders related to emotional dysregulation. Int J Neuropsychopharmacol 10: 309-320.

Gutknecht L, Waider J, Kraft S, Kriegebaum C, Holtmann B, Reif A et al (2008). Deficiency of brain 5-HT synthesis but serotonergic neuron formation in Tph2 knockout mice. J Neural Transm 115: 1127-1132.

Haghighi F, Bach-Mizrachi H, Huang YY, Arango V, Shi S, Dwork AJ et al (2008). Genetic architecture of the human tryptophan hydroxylase 2 gene: existence of neural isoforms and relevance for major depression. Mol Psychiatry 13: 813-820.

Hinvest NS, Anderson IM (2009). The effects of real $v s$ hypothetical reward on delay and probability discounting. Q J Exper Psychol 29: 1-13.

Ho MY, Mobini S, Chiang TJ, Bradshaw CM, Szabadi E (1999). Theory and method in the quantitative analysis of impulsive choice' behaviour: implications for psychopharmacology. Psychopharmacology (Berl) 146: 362-372.

Holt DD, Green L, Myerson J (2003). Is discounting impulsive?. Evidence from temporal and probability discounting in gambling and non-gambling college students. Behav Processes 64: 355-367.

Homberg JR, van den BR, den Heijer E, Suer R, Cuppen E (2008). Serotonin transporter dosage modulates long-term decisionmaking in rat and human. Neuropharmacology 55: 80-84.

Hunt IM, Silman AJ, Benjamin S, McBeth J, Macfarlane GJ (1999). The prevalence and associated features of chronic widespread pain in the community using the 'Manchester' definition of chronic widespread pain. Rheumatology (Oxford) 38: 275-279.

John OP, Donahue EM, Kentle RL (1991). The Big Five InventoryVersions $4 a$ and 54. University of California, Berkeley, Institute of Personality and Social Research: Berkeley.

Jollant F, Buresi C, Guillaume S, Jaussent I, Bellivier F, Leboyer M et al (2007). The influence of four serotonin-related genes on decision-making in suicide attempters. Am J Med Genet B Neuropsychiatr Genet 144: 615-624.

Juhasz G, Chase D, Pegg E, Downey D, Toth ZG, Stones K et al (2009). CNR1 Gene is associated with high neuroticism and low agreeableness and interacts with recent Negative Life Events to predict current depressive symptoms. Neuropsychopharmacology 34: 2019-2027.

Ke L, Qi ZY, Ping Y, Ren CY (2006). Effect of SNP at position 40237 in exon 7 of the TPH2 gene on susceptibility to suicide. Brain Res 1122: $24-26$.

Lemonde S, Turecki G, Bakish D, Du L, Hrdina PD, Bown CD et al (2003). Impaired repression at a 5-hydroxytryptamine $1 \mathrm{~A}$ receptor gene polymorphism associated with major depression and suicide. J Neurosci 23: 8788-8799.

Lesch KP, Bengel D, Heils A, Sabol SZ, Greenberg BD, Petri S et al (1996). Association of anxiety-related traits with a polymorphism in the serotonin transporter gene regulatory region. Science 274: 1527-1531.

Li D, He L (2006). Further clarification of the contribution of the tryptophan hydroxylase (TPH) gene to suicidal behavior using systematic allelic and genotypic meta-analyses. Hum Genet 119: 233-240.

Lim JE, Pinsonneault J, Sadee W, Saffen D (2007). Tryptophan hydroxylase 2 (TPH2) haplotypes predict levels of TPH2 mRNA expression in human pons. Mol Psychiatry 12: 491-501.

Lin YM, Chao SC, Chen TM, Lai TJ, Chen JS, Sun HS (2007). Association of functional polymorphisms of the human tryptophan hydroxylase 2 gene with risk for bipolar disorder in Han Chinese. Arch Gen Psychiatry 64: 1015-1024.

Lopez dL, Brezo J, Rouleau G, Lesage A, Dumont M, Alda M et al (2007a). Effect of tryptophan hydroxylase-2 gene variants on suicide risk in major depression. Biol Psychiatry 62: 72-80.

Lopez VA, Detera-Wadleigh S, Cardona I, Kassem L, McMahon FJ (2007b). Nested association between genetic variation in 
tryptophan hydroxylase II, bipolar affective disorder, and suicide attempts. Biol Psychiatry 61: 181-186.

Mann JJ, Currier D, Murphy L, Huang YY, Galfalvy H, Brent D et al (2008). No association between a TPH2 promoter polymorphism and mood disorders or monoamine turnover. J Affect Disord 106: $117-121$.

Mobini S, Chiang TJ, Ho MY, Bradshaw CM, Szabadi E (2000). Effects of central 5-hydroxytryptamine depletion on sensitivity to delayed and probabilistic reinforcement. Psychopharmacology (Berl) 152: 390-397.

Munafo MR, Freimer NB, Ng W, Ophoff R, Veijola J, Miettunen J et al (2009). 5-HTTLPR genotype and anxiety-related personality traits: a meta-analysis and new data. Am J Med Genet B Neuropsychiatr Genet 150B: 271-281.

Murphy SE, Longhitano C, Ayres RE, Cowen PJ, Harmer CJ, Rogers RD (2008). The role of serotonin in nonnormative risky choice: the effects of tryptophan supplements on loss-aversion in healthy adult volunteers. J Cogn Neurosci 21: 1709-1719.

Must A, Juhasz A, Rimanoczy A, Szabo Z, Keri S, Janka Z (2007). Major depressive disorder, serotonin transporter, and personality traits: why patients use suboptimal decision-making strategies? J Affect Disord 103: 273-276.

Ono H, Shirakawa O, Kitamura N, Hashimoto T, Nishiguchi N, Nishimura A et al (2002). Tryptophan hydroxylase immunoreactivity is altered by the genetic variation in postmortem brain samples of both suicide victims and controls. Mol Psychiatry 7: $1127-1132$.

Paulus MP (2007). Decision-making dysfunctions in psychiatryaltered homeostatic processing? Science 318: 602-606.

Paulus MP, Rogalsky C, Simmons A, Feinstein JS, Stein MB (2003). Increased activation in the right insula during risk-taking decision making is related to harm avoidance and neuroticism. Neuroimage 19: 1439-1448.

Rachlin H, Logue AW, Gibbon J, Frankel M (1986). Cognition and behavior in studies of choice. Psychol Rev 93: 33-45.

Reuter M, Kuepper Y, Hennig J (2007). Association between a polymorphism in the promoter region of the TPH2 gene and the personality trait of harm avoidance. Int J Neuropsychopharmacol 10: 401-404.

Rijsdijk FV, Sham PC, Sterne A, Purcell S, McGuffin P, Farmer A et al (2001). Life events and depression in a community sample of siblings. Psychol Med 31: 401-410.

Rogers RD, Everitt BJ, Baldacchino A, Blackshaw AJ, Swainson R, Wynne $\mathrm{K}$ et al (1999). Dissociable deficits in the decisionmaking cognition of chronic amphetamine abusers, opiate abusers, patients with focal damage to prefrontal cortex, and tryptophan-depleted normal volunteers: evidence for monoaminergic mechanisms. Neuropsychopharmacology 20: 322-339.

Rogers RD, Tunbridge EM, Bhagwagar Z, Drevets WC, Sahakian BJ, Carter CS (2003). Tryptophan depletion alters the decisionmaking of healthy volunteers through altered processing of reward cues. Neuropsychopharmacology 28: 153-162.

Roiser JP, de Martino B, Tan GC, Kumaran D, Seymour B, Wood NW et al (2009). A genetically mediated bias in decision making driven by failure of amygdala control. J Neurosci 29: 5985-5991.

Roiser JP, Rogers RD, Cook LJ, Sahakian BJ (2006). The effect of polymorphism at the serotonin transporter gene on decisionmaking, memory and executive function in ecstasy users and controls. Psychopharmacology (Berl) 188: 213-227.

Savelieva KV, Zhao S, Pogorelov VM, Rajan I, Yang Q, Cullinan E et al (2008). Genetic disruption of both tryptophan hydroxylase genes dramatically reduces serotonin and affects behavior in models sensitive to antidepressants. PLoS ONE 3: e3301.
Scheuch K, Lautenschlager M, Grohmann M, Stahlberg S, Kirchheiner J, Zill P et al (2007). Characterization of a functional promoter polymorphism of the human tryptophan hydroxylase 2 gene in serotonergic raphe neurons. Biol Psychiatry 62: $1288-1294$.

Shifman S, Bhomra A, Smiley S, Wray NR, James MR, Martin NG et al (2008). A whole genome association study of neuroticism using DNA pooling. Mol Psychiatry 13: 302-312.

Smoski MJ, Lynch TR, Rosenthal MZ, Cheavens JS, Chapman AL, Krishnan RR (2008). Decision-making and risk aversion among depressive adults. J Behav Ther Exp Psychiatry 39: $567-576$.

Storey JD, Tibshirani R (2003). Statistical significance for genomewide studies. Proc Natl Acad Sci USA 100: 9440-9445.

Strobel A, Dreisbach G, Muller J, Goschke T, Brocke B, Lesch KP (2007). Genetic variation of serotonin function and cognitive control. J Cogn Neurosci 19: 1923-1931.

Strobel A, Gutknecht L, Rothe C, Reif A, Mossner R, Zeng Y et al (2003). Allelic variation in 5-HT1A receptor expression is associated with anxiety- and depression-related personality traits. J Neural Transm 110: 1445-1453.

Talbot PS, Watson DR, Barrett SL, Cooper SJ (2006). Rapid tryptophan depletion improves decision-making cognition in healthy humans without affecting reversal learning or set shifting. Neuropsychopharmacology 31: 1519-1525.

Van Den Bogaert A, Sleegers K, De Zutter S, Heyrman L, Norrback $\mathrm{KF}$, Adolfsson $\mathrm{R}$ et al (2006). Association of brain-specific tryptophan hydroxylase, TPH2, with unipolar and bipolar disorder in a Northern Swedish, isolated population. Arch Gen Psychiatry 63: 1103-1110.

Walderhaug E, Magnusson A, Neumeister A, Lappalainen J, Lunde $\mathrm{H}$, Refsum $\mathrm{H}$ et al (2007). Interactive effects of sex and 5-HTTLPR on mood and impulsivity during tryptophan depletion in healthy people. Biol Psychiatry 62: 593-599.

Walther DJ, Peter JU, Bashammakh S, Hortnagl H, Voits M, Fink H et al (2003). Synthesis of serotonin by a second tryptophan hydroxylase isoform. Science 299: 76.

Zhang X, Gainetdinov RR, Beaulieu JM, Sotnikova TD, Burch LH, Williams RB et al (2005). Loss-of-function mutation in tryptophan hydroxylase-2 identified in unipolar major depression. Neuron 45: 11-16.

Zhou Z, Roy A, Lipsky R, Kuchipudi K, Zhu G, Taubman J et al (2005). Haplotype-based linkage of tryptophan hydroxylase 2 to suicide attempt, major depression, and cerebrospinal fluid 5-hydroxyindoleacetic acid in 4 populations. Arch Gen Psychiatry 62: 1109-1118.

Zill P, Baghai TC, Zwanzger P, Schule C, Eser D, Rupprecht R et al (2004a). SNP and haplotype analysis of a novel tryptophan hydroxylase isoform (TPH2) gene provide evidence for association with major depression. Mol Psychiatry 9: $1030-1036$

Zill P, Buttner A, Eisenmenger W, Moller HJ, Ackenheil M, Bondy B (2007a). Analysis of tryptophan hydroxylase I and II mRNA expression in the human brain: a post-mortem study. J Psychiatr Res 41: 168-173.

Zill P, Buttner A, Eisenmenger W, Moller HJ, Bondy B, Ackenheil M (2004b). Single nucleotide polymorphism and haplotype analysis of a novel tryptophan hydroxylase isoform (TPH2) gene in suicide victims. Biol Psychiatry 56: 581-586.

Zill P, Preuss UW, Koller G, Bondy B, Soyka M (2007b). SNP- and haplotype analysis of the tryptophan hydroxylase 2 gene in alcohol-dependent patients and alcohol-related suicide. Neuropsychopharmacology 32: 1687-1694.

Supplementary Information accompanies the paper on the Neuropsychopharmacology website (http://www.nature.com/npp) 